\title{
Preface: \\ Reflections on a Career in Health Research, International Collaboration and Mentoring
}

\author{
Salim Yusuf, MD, DPhil, FRCP ${ }^{1}$
}

Key Words: Cardiovascular disease, global health, health research, training

Recommended Citation: Yusuf S. Preface: reflections on a career in health research, international collaboration and mentoring. Public Health Reviews. 2012;33:362-72.

\section{BACKGROUND}

I had been training in India when I received a Rhodes Scholarship to go to Oxford. My interest as a medical student was in cardiology and at Oxford my initial goal was to work in pediatric cardiology. However, the pediatric cardiologist with whom I had corresponded fell ill and I had to go into another field. In the end, I worked with Professor Peter Sleight and Professor Richard Peto studying how beta-blockers reduced infarct size and acute infarction and saved lives. We did a series of studies that started with how to measure infarct size in people and how to administer the beta-blockers and their impact on different measures of infarct sizes and then ultimately the large First International Study of Infarct Survival (ISIS 1) with 16,000 people that looked at beta-blockers saving lives in acute infarction. ${ }^{1}$ That then got me heavily into large-scale clinical trials and we were the first group that did meta-analysis in clinical medicine; these two tools, taking about ten years of work, got me started.

I then did my clinical training in cardiology after which I went to the National Institutes of Health (NIH) in Bethesda, MD. There I had the opportunity to cover the World's first major program in heart failure, which was called the Studies of Left Ventricular Dysfunction (SOLVD). ${ }^{2}$ I used my knowledge in acute infarction as well as cardiology to help the NIH set

\footnotetext{
${ }^{1}$ Director, Population Health Research Institute, McMaster University, Hamilton, Ontario, Canada.
} 
up this major program and it became a landmark program that then set the stage for a series of studies using the same approach in heart failure. These studies were shown to save lives, prevent heart failure and prevent hospitalization and it is now standard therapy in medical practice.

During this time period, I got a much broader view of cardiovascular research because the NIH is such a fantastic place. So much is happening and they have so many top-notch people coming through that it is almost like a focal point where ideas are boiling. It was a great experience and I helped design other studies in atherosclerosis preventing arrhythmias and saw my colleagues work in hypertension and in cholesterol lowering. As a result, I got a very broad exposure to the important issues in research at $\mathrm{NIH}$ while at the same time focusing on a few ideas of my own.

\section{GLOBAL PROGRAMS}

In 1992, I came to Canada and joined McMaster University as head of cardiology where we started up a couple of programs that are now in 84 countries and that is about the time that I started to get a feel for global health. Previously, two or three years before I left NIH, I developed an interest in why south Asians develop premature heart disease as work I began with colleagues in India, Dr. Pais and others. ${ }^{3}$ Gradually we chipped away at that problem and it was the origins of the global study called INTERHEART that was done in 52 countries. ${ }^{4}$ That study looked at the causes of heart attacks and we were surprised to find that nine simple risk factors could account for most of the risk of heart attacks and that it was the same risk factors that mattered in people around the world. Today both findings are accepted as given but 15 years ago people did not think that way. This made prevention very easy; you just have essentially similar types of preventions globally but customized to local economic and cultural settings.

We have followed the INTERHEART study with an ongoing large study on stroke (INTERSTROKE) that now has about 20,000 people and about 40 countries involved. ${ }^{5}$ In the coming year, we will finish the study with approximately 25,000 people, looking at the causes of stroke worldwide. However, a stroke is much more complicated than heart attacks because stroke is a heterogeneous condition. It involves hemorrhagic and ischemic stroke and even within each broad category ischemic strokes have different kinds of strokes and hemorrhagic strokes have different kinds of hemorrhagic strokes. Consequently, you require a lot of people with each kind of stroke to understand it; INTERSTOKE will provide great insights into that. 
Around the same time we also set up the large Prospective Urban Rural Epidemiology (PURE) Study, which has about 400,000 people in 17 countries and about 620 communities. We are looking at how a changing environment, especially societal contrasts, had an impact on health habits and risk factors for cardiovascular disease. ${ }^{6}$ Out of the 400,000 people, about 156,000 adults are being followed long term. We are just finishing five-year follow up with many papers being written right now.

In my work we have also gone from detecting risk factors to work involving modification of risk factors to see if that is able to prevent heart attacks and strokes. We have had a series of studies on cholesterol lowering, different forms of blood pressure lowering like the Heart Outcomes Prevention Evaluation (HOPE) Study, testing vitamins, which we have shown repeatedly are pretty useless and testing a number of other hypotheses. ${ }^{7,8}$ In addition, we have moved into other fields like atrial fibrillation and heart failure and various others. Thus, we have an active program globally on understanding the causes of heart disease but also how to modify it.

More recently, about three years back, we started a program on what is called knowledge translation, which is implementation. It follows naturally; if you look at the impact of the trials that we have, the clinical utilization of our findings from research is relatively modest and slow. We now are trying to find why that is the case, how we can speed it up and how research findings can be translated into medical practice faster. Some people call it implementation science some call it knowledge translation; we deal with the whole range of it.

Also in the last five years, in order to understand the causation of heart disease and stroke, we have started to look into understanding genetic and environmental components and how they interact. We have published a handful of papers so far, but really the program is now swinging and I think that will publish quite a lot of interesting findings.

We are now moving into other forms of heart disease; what I call orphan diseases like Chagas disease in South America. Chagas disease affects about eight to ten million people with no known treatments for it because nobody has done any proper evaluation of the stages of the disease progression. We are running the World's largest study evaluating treatments in Chagas disease with 2700 people enrolled and about a four-year or fiveyear follow up and we will get the result of that in about a year. We have another ongoing study on TB pericarditis in Africa; another orphan condition for which nothing has been clearly proven to be effective. In this case we are looking at treatment with steroids as well as a new vaccine. You can start to see that we are moving into research on diseases that do not affect Canadians 
or North Americans, but rather poor people around the world and there are a range of methodologies and a range of studies underway. Right now we are running about 35 medium- to large-scale studies.

\section{THE POPULATION HEALTH RESEARCH INSTITUTE}

The Population Health Research Institute was originally known as the Preventive Cardiology and Therapeutics Research Program when it was first created some 20 years ago. About ten years back it grew and we called ourselves the Population Health Research Institute. It is a group that I founded and head up and it has about 250 researchers in research teams, large by Canadian standards and we are making a fair impact. We have about 30 investigators; they are a very dynamic, committed and motivated set of people.

We link with people in diabetes, kidney disease, stroke, infectious diseases, health policy, and knowledge translation. Recently, we began collaborations with the engineering department to look at issues of water safety, environment and health. We are collaborating with experts in gastrointestinal diseases because there is a theory that microbes or what is called the microbiome has an effect on modulating obesity. So there is a lot of lateral thinking in our group, a lot of external collaboration and we work on a range of research around the world.

I think our key strength is our ability to absorb other people's ideas and collaborate; that is how we grow. We have about 20 scientists who collaborate with us closely that are not based at Hamilton, Canada but come for one or two weeks per year and work and communicate with us through long distance e-mails the remainder of the time. There are people in about 50 different countries with whom we have collaborated with in study after study and who helped us set up our networks. So the Institute is fairly universal not in terms of geography alone but in the broad way we think. We do not work in silos; we collaborate between groups within the Institute and across with other groups at other universities. That has been our strength. We learn from other people all the time.

\section{CHALLENGES AND BENEFITS OF WORKING GLOBALLY}

There are obviously challenges to working on a global scale. The biggest challenge is raising enough money because it is difficult to find money for global studies. Organizations generally give you money for one country and 
usually the country you live in. The second challenge is obviously the regulatory, contractual bureaucracy that we have to deal with. It is a huge job, but we learned how to deal with it and we employ people with expertise in it.

However, the benefits are that you are doing work that has global applicability. You are influencing health and related policy worldwide. These studies have global impact and ultimately it is very satisfying because you are working with highly selected people who are incredibly motivated around the world - in India, China, Africa or South America working with us, these are people who do not have to do it. They are paid a very little, but we just enjoy the collaboration and the opportunities. These are some of the finest people both in terms of intellect and heart with what they really want to do and their priorities. Participating internationally is one of the most humiliating and gratifying parts of my work because the enthusiasm for the questions people ask is so much oriented towards the right thing: How do we solve a major problem?

For almost all our studies the funding we get does not cover the cost of doing the work, not even half the cost and our collaborators worldwide scrape together funds to supplement what we provide. So on one hand there is a challenge and on another hand there is an opportunity. It is hand to mouth, but we have managed to keep many of our global studies going now for 20 years so hopefully it will keep on going for a longer time.

\section{TRANSLATION FROM SCIENCE INTO PRACTICE}

We have had a number of results that have been accepted and gradually incorporated into practice. The issue is not that we do not see translation of our results, it is a matter of to what degree do you have an impact and how broad is the impact. For instance, we were one of the groups that showed that ACE inhibitors saved lives and prevented heart attacks and strokes in people with and without heart failure and irrespective of any other criteria. Our results have been accepted worldwide, they are in every guideline for secondary prevention and have been approved by regulators in many countries around the world. But, if you look at the use of these drugs after a heart attack, usage is initially high to prevent heart failure after somebody who has come to the hospital. Then, if you look at the group of people with the same condition five years out from an event, there is a drop off in use of these treatments, which need to be taken for life. Globally only ten to 20 percent of people are receiving treatment. Even in wealthy countries like Canada only about 25 to 30 percent are receiving it and in poor countries it is under five percent. 
The gap in treatment usually happens when people stop getting in contact with the health care system. This is even the case with simple aspirin; if you take a country like India or China only five to ten percent of people after a heart attack or stroke are receiving aspirin long-term. I think the issues are related to a lack of knowledge and a lack of a system. There is no system to ensure long-term care and there are costs associated with going to see health practitioners. If you have to go and see a doctor to get your aspirin renewed, the cost of going to see the doctor is many times the cost of aspirin.

We need new systems in place, so we are working with a group of people to propose community projects to try to overcome the barriers in the system. The systemic barriers are the ones that we need to deal with. For common conditions having a physician centric approach is not going to work; there are not enough physicians and even the cheapest physician is far too expensive to deal with an epidemic. One of our goals is to promote the concept of health shifting. Some of the simple things physicians are doing can be given to less highly trained people and what they are doing is shifted down so everything will ratchet down a notch. Hopefully with this approach you can improve access and decrease cost and therefore you increase impact. Therefore, a lot of our current work is on how do we take current knowledge and make sure it is utilized to a greater extent on a sustained basis in practice.

\section{OVERCOMING DIFFICULTIES IN RESOURCE CHALLENGED SETTINGS}

As discussed before, funds are the main challenge to implementing work in resource challenged locations, another is finding the qualified personnel. Although, we have found that because our studies are very simple, even in sub Saharan Africa or in rural Sudan, we can find people who can carry out our protocols very well. Obviously quality control is a big issue, supervision is a big issue and I think the key thing in all of this is personal contact. We have strong personal relationships with key people in each country, who in turn have strong personal relationships with key investigators in different parts of the country, who in their turn have good relationship with people at the grassroots level. A chain of good relationships is key and it can overcome a lot of problems.

A third difficulty is the logistics of what we do and by and large we have been able to overcome this by having innovative means of blood collection, shipment and processing at low cost. 
Bureaucracy becomes another big challenge as many developing countries are putting up new barriers to international collaborations, partly because some people from the West have abused their privileges and have done studies that may be unethical or even if ethical, they did not get the right approvals. This then raises concerns ; walls get put up and what would normally take one month to start a study now takes a year or two to get the approvals. Increasing bureaucracy and regulations in different countries is a major challenge.

And the other challenge is finding enough young motivated people to go into serious health research and the point is the word "serious". Because to become a good health researcher you must throw yourself in for ten years before you can even say you have the chance to become a good researcher. That is a long slog after someone has done their medical school and residency. Essentially you are telling them they have done ten years of training in medical school and residency and now here is ten more years of training. Very few people are made out for it and that is perfectly OK, in the end we do it because the benefits outweigh the challenges and it is a fun thing to do. One of my biggest satisfactions is training people, helping them grow and seeing them succeed.

\section{ENCOURAGING YOUNG PEOPLE IN HEALTH RESEARCH}

I think the key thing when we look to encourage young people to go into health research is that we cannot influence the innate sense of altruism that some people have and others do not. But, let's say we take somebody who has a fair modicum of it, a fair degree of intelligence, a fair degree of curiosity and a willingness to come and work with people on important questions; what I can do is create an environment in which we can promote their success. We have dealt with quite a few people this way and usually when they see they are benefiting and helping other people then you create a virtuous chain reaction. One generation helps the next and that generation helps the one to follow it.

Not everybody who is helped will help others but there are enough people who will do it. I benefited enormously from my mentors and professors; Professors Peter Sleight and Richard Peto, my colleague Rory Collins with whom I collaborated while I was at Oxford, and several people who helped me when I was at NIH. It is personal example in inspiring people that this is a wonderful way to live one's life and with the field that I am in, I can see the benefits to people, to patients and to the public. You can see the health statistics showing decreased mortality and I feel blessed in 
what I am dong and I think many of the people around me share that feeling. We do not need a large number of people doing any kind of research, what you want is people who are very committed and motivated and who work on a sustained basis. I really think that most physicians should really just be good doctors and look after patients; that is what we are there for. And a few committed and excellent people going into health research is a good idea.

\section{FUTURE GOALS AND DIRECTIONS FOR RESEARCH}

I always have future directions for research for the next five or ten years, but they keep on changing. I will continue with my global health work because that is what I am passionate about, but increasingly I am looking into new interfaces. For instance knowledge translation, we now have a number of projects in this area and some of my recent grants have had a large emphasis on that. Another part is looking at the legal and social issues and how they effect the implementation of our programs. A third one is working with engineers and biologists in developing point of care devices to diagnose at low cost in remote settings. I also find it intellectually stimulating to collaborate with my colleagues who are working in genetics. Although I have reservations on how much it will improve human health at least in CVD and in the next decade, genetics can provide useful and novel insights into biology if done intelligently. I continue to work on strokes and diabetes and obesity. I continue to lead a few studies, but increasingly I help younger people set up major studies and provide advice, support and sometimes financing to help them get started in the form of seed money. So my role has evolved to creating structures and an environment where others can succeed. It is a role I enjoy while I continue to do research.

\section{ADVICE TO YOUNG RESEARCHERS}

I think that my advice to those entering the field is to have a dream and to focus on it. Do not try to have too many dreams because then you cannot achieve anything. Identify a team of people or an individual that you can relate to that works in your field of interest and take a question and work through it systematically. I often find young people trying to be involved in eight or ten projects and they feel very proud that they are very busy, but that usually means they are not achieving much in anything. I usually tell young people take one project, focus and run with it and once you are really smart and have learned a lot then you can do a little bit of diversification. 
Do not do what I am doing now (i.e., working in many projects), stay very focused as I did during the first decade and half of my career.

I also warn them that this is a long haul; to make progress on any important question takes many years. We will help them, but they themselves need to be ready to commit to the long haul.

My role is in nurturing them so that they succeed; in health research you have more failures than successes. So I try to be a counselor, helping tide young people through rejections of grants and papers. Despite these types of setbacks, the work is important and we can find another way to get something done. We have grants that were funded on the sixth attempt and because it was important we persisted. So we teach young people persistence.

My advice to young people is to think of one or two important questions, but do not think of small questions or forty questions. Focus on one important question, and devote the next several years of your life trying to make advancements there. And people must do this with their eyes open. Research is a reasonable living, nobody is going to be poor, but people need to understand, for a physician especially, you are going to make less than your colleagues who are in clinical practices. That is a choice one voluntarily makes. Most people accept it and they know they are having fun.

\begin{abstract}
About the Author: Dr. Yusuf, a graduate of St. John's Medical College, Bangalore University, India, was awarded a Rhodes Scholarship that took him to Oxford where he completed a doctorate and underwent clinical training in cardiology, and coordinated the first ISIS trial. In 1984, he moved to the National Institutes of Health as a scientific project officer of several landmark studies (SOLVD, DIG, and the post-CABG studies).. Dr. Yusuf became Acting Chief of the Clinical Trials Branch of the National Heart, Lung, and Blood Institute (NHLBI) and held a number of appointments at the Uniformed Services, University of Health Sciences. In 1992, Dr. Yusuf became Director of the Division of Cardiology, McMaster University, and Director of the Preventive Cardiology and Therapeutic Program, Hamilton Civic Hospitals Research Centre; in 1999, he became the Director of the Population Health Research Institute; he is also Professor of Medicine. He has been the principal investigator and chairman of several major trials such as HOPE, OASIS, RESOLVD, INTERHEART, SHARE, PURE, INTERSTROKE, etc. Dr. Yusuf has conducted studies in Canada, India, and 50 other countries. He holds an endowed Chair for Research from the Heart and Stroke Foundation of Ontario and is a senior scientist of the Canadian Institute of Health Research. Dr. Yusuf has published more than 700 papers, and edits the Journal of Evidence-Based Cardiology and Textbook of Evidence-Based Cardiovascular Medicine.
\end{abstract}

Dr. Yusuf has received many international awards These include the Prix Galien award 2001, the Gold Medal of the European Society of Cardiology 2008 and the Clinical Research Prize of the American Heart Association in 2008, among 25 other international awards. He was the second highest cited scientist (Thompson Science Watch) in 2011 and has recently been elected as the President elect of the World Heart Federation. 


\section{REFERENCES}

1. No authors listed. Randomised trial of intravenous atenolol among 16027 cases of suspected acute myocardial infarction: ISIS-1. First International Study of Infarct Survival Collaborative Group. Lancet. 1986;2:57-66.

2. No authors listed. The Studies of Left Ventricular Dysfunction (SOLVD): Limited Access Database. Version 2.0. Available from URL: https://biolincc.nhlbi. nih.gov/static/studies/solvd/LAD_Overview.pdf (accessed 25 June 2012).

3. Pais P, Pogue J, Gerstein H, Zachariah E, Savitha D, Jayprakash S, Nayak PR, Yusuf S. Risk factors for acute myocardial infarction in Indians: a casecontrol study. Lancet. 1996;348:358-63.

4. INTER-HEART: A Global Case-Control Study of Risk Factors for Acute Myocardial Infarction. Available from URL: http://www.phri.ca/interheart/ (accessed 25 June 2012).

5. INTERSTROKE: A Study of the Importance of Conventional and Emerging Risk Factors of Stroke in Different Regions and Ethnic Groups of the World. Available from URL: http://www.phri.ca/body.cfm?id=235 (accessed 25 June 2012).

6. Teo K, Chow CK, Vaz M, Rangarajan S, Yusuf S; PURE Investigators-Writing Group. The Prospective Urban Rural Epidemiology (PURE) study: examining the impact of societal influences on chronic noncommunicable diseases in low-, middle-, and high-income countries. Am Heart J. 2009;158:1-7.

7. Yusuf S, Sleight P, Pogue J, Bosch J, Davies R, Dagenais G. Effects of an angiotensin-converting-enzyme inhibitor, ramipril, on cardiovascular events in high-risk patients. The Heart Outcomes Prevention Evaluation Study Investigators. N Engl J Med. 2000;342:145-53.

8. Yusuf S, Dagenais G, Pogue J, Bosch J, Sleight P. Vitamin E supplementation and cardiovascular events in high-risk patients. The Heart Outcomes Prevention Evaluation Study Investigators. N Engl J Med. 2000;342:154-60 